\title{
Projeto Uni: cenário de aprender, pensar e construir a interdisciplinaridade na prática pedagógica da Enfermagem
}

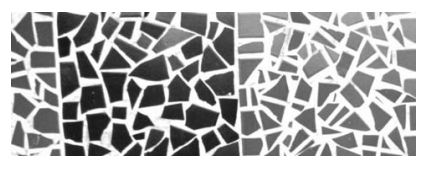

\author{
Roseni Rosângela de Sena ${ }^{1}$ \\ Juliana Carvalho de Araújo Leite ${ }_{3}^{2}$ \\ Kênia Lara da Silva ${ }_{4}^{3}$ \\ Fabíola Moura da Costa
}

SENA, R. S.; LEITE, J. C. A.; SILVA, K. L.; COSTA, F. M. Uni Project: a background in which to learn, think and build interdisciplinarity in teaching nursing, Interface - Comunic, Saúde, Educ, v.7, n.13, p.79-90, 2003.

The study examines the incorporation of the interdisciplinary approach in two nursing courses in Brazil that pursue UNI Projects. It is a descriptive, qualitative study, using historical dialectic materialism as its theoretical framework. Its purpose was to examine the changes that have taken place in the teaching of the nursing courses, with emphasis on interdisciplinarity. The primary data was gathered using interviews by focus groups, teachers and students of the courses and nurses in service. The secondary sources were obtained through an examination of curriculums and other documents available in these schools. It was found that the courses are using interdisciplinarity as a strategy to substitute the organization of the curriculum by subject. The teachers described the difficulties of working from this point of view, indicating biological training as one of the determinants of this difficulty. They concluded that the emphasis on interdisciplinarity and team work has demanded the adoption of active teaching methods and has contributed to the change to the nursing teaching model in the university investigated.

KEY WORDS: Teaching; Nursing; interdisciplinarity; professional practice.

Investiga-se a incorporação do enfoque interdisciplinar em dois cursos de Enfermagem no Brasil, que desenvolvem o Projeto UNI. Trata-se de pesquisa qualitativa, com referencial teórico-metodológico crítico. Teve como objetivo analisar as transformações ocorridas no processo de ensino desses cursos, tendo como ênfase a interdisciplinaridade. Os dados primários foram levantados utilizando a técnica de grupo focal, junto a docentes e alunos dos cursos das escolas cenários da pesquisa. Os dados de fonte secundária foram obtidos da análise documental de currículos e de outros documentos de ensino disponíveis nessas escolas. Resultados evidenciam que os cursos estão utilizando a interdisciplinaridade como estratégia para a superação da organização do currículo por disciplina. Os docentes relatam as dificuldades do trabalho sob esse enfoque, apontando a formação biologicista como um dos determinantes dessa dificuldade. Conclui-se que a ênfase na interdisciplinaridade e no trabalho em equipe tem exigido a adoção de metodologias ativas de ensino e contribuído para a transformação do modelo de ensino de Enfermagem vigente nas universidades investigadas.

PALAVRAS-CHAVE: Ensino; Enfermagem; interdisciplinaridade; prática profissional.

\footnotetext{
${ }_{1}^{1}$ Professora e Diretora da Escola de Enfermagem, Universidade Federal de Minas Gerais (EEUFMG), Coordenadora do NUPEPE. $<$ roseni@enf.ufmg.br>

${ }^{2}$ Enfermeira, Secretaria Municipal de Saúde, Belo Horizonte. <denis@spress.com>

${ }^{3}$ Aluna, $8^{\circ}$ período da EEUFMG; bolsista de IC/CNPq. <kenia.silva@globo.com>

${ }^{4}$ Enfermeira, Secretaria Municipal de Saúde, Ribeirão das Neves, MG. <fabiola@enf.ufmg.br>
} 


\section{Introdução}

A inovação pedagógica desenvolvida pelos educadores de saúde em diferentes instituições de ensino no país em particular na formação dos profissionais da área, encontra suporte na interdisciplinaridade e tem contribuído para a construção de uma escola participativa e decisiva na preparação de alunos como sujeitos sociais. Para Gadotti (1982), o objetivo da interdisciplinaridade é a experimentação de vivências de uma realidade global, inserida nas experiências cotidianas do aluno, do professor e do povo, a qual, na teoria positivista, é compartimentalizada e fragmentada.

Observam-se práticas pedagógicas no ensino de Enfermagem que buscam construir o saber pela articulação das várias vivências, sejam elas originadas na escola, na família, na comunidade ou em qualquer outro grupo social. Essas práticas inovadoras na educação em Enfermagem objetivam construir a interdisciplinaridade que é traduzida, efetivamente, por um trabalho coletivo $e$ solidário na organização da escola e, especialmente, do processo ensinoaprendizagem.

A interdisciplinaridade se desenvolveu em diversos campos e, de certo modo, contraditoriamente, até especializou-se, caindo na armadilha que visava evitar ou que se propunha superar. A educação incorporou e disseminou o conceito de interdisciplinaridade de forma particular, o que culminou com o reconhecimento de sua importância em diferentes campos do conhecimento (Demo, 1998).

Analisar o processo ensino-aprendizagem tem sido uma tarefa prioritária de investigadores na área de educação como Bordenave \& Pereira (2001), Demo (1998), Gadotti (1982, 2000), Sacristán \& Gómez (1998), cujos ideais e proposições têm sido utilizados para inovação do ensino na área da saúde. Nas duas últimas décadas, a produção científica sobre o tema tem contribuído para a construção de um novo paradigma da educação.

O presente trabalho orienta-se pela concepção de que a educação não pode ser interpretada apenas à luz das teorias do comportamento humano, mas deve se sustentar no conteúdo principal da vida humana, de suas transformações e das potencialidades dos sujeitos em construir uma nova história. Defende-se a idéia de que a educação deve se desenvolver em estreito vínculo com as necessidades concretas de vida, considerando as atividades culturais e o modo de produção hegemônico na sociedade. Conforme analisam Bordenave \& Pereira (2001), Demo (1998), Sacristán \& Gómez (1998), Gadotti (2000), a teoria pedagógica idealista se apóia em conceitos, arbitrariamente eleitos e constantes, de homem $e$ de representações subjetivas, impossíveis de se dominar, não podendo responder à grande contradição de educar para a vida em sociedades orientadas para o consumo de bens materiais e para um comportamento cada vez mais individualista.

Acredita-se, assim, que a configuração da existência humana e de sua atividade social própria caracteriza a concepção de sujeito histórico-social $e$ culturalmente determinado. Nesse contexto, a educação é parte tanto do ambiente, quanto da consciência desse sujeito e deve se concretizar como prática transformadora (Bordenave \& Pereira, 2001; Demo, 1998; Gadotti, 2000).

Para explicitar a orientação de educação como prática social, este estudo apóia-se na explicação de Vásquez (1997), que discute a práxis humana como uma tradução da produção e da auto-criação do ser humano configurando-se, 
assim, como práxis criadora. A compreensão desse conceito permite conhecer como os homens $e$ as mulheres enfrentam novas necessidades e novas situações, estabelecendo o ciclo de inventar e recriar, próprio da natureza humana, que deveria se expressar na educação plena e libertadora. Para Vásquez (1997), toda práxis é uma ação criadora sobre a matéria, sendo fundamental distinguir a práxis imitativa, reiterativa ou espontânea, da práxis reflexiva ou criadora.

Para construir uma reflexão, deve-se tomar como pressuposto a adoção dos modelos de ensino-aprendizagem de caráter interdisciplinar, assumidos neste estudo como uma possibilidade conceitual e uma ferramenta no campo da educação de profissionais de saúde, em particular da Enfermagem.

Foram tomados como referência para realizar a pesquisa de campo os Projetos "Uma Nova Iniciativa na Formação dos Profissionais de Saúde" Projetos UNI, caracterizados pelo movimento de transformação do ensino dos profissionais para o setor saúde, com propostas de forte potencialidade para mudanças do modelo de ensino na área (Almeida et al., 1999).

Os Projetos UNI, desenvolvidos em países da América Latina desde a década de 1990, vêm experimentando a conceitualização e execução de uma nova possibilidade de pensar e fazer a educação dos profissionais do setor saúde. Suas proposições aproximam-se do pensamento da práxis criadora / transformadora que pode ser observada em muitas dimensões, mas adquire expressão máxima na luta pela reestruturação ou transformação dos modelos político-pedagógicos dos cursos das instituições que integram o Projeto.

Definiram-se como cenários dois cursos de Enfermagem que estão construindo novos modelos, caracterizados, em sua singularidade, por projetos pedagógicos diferenciados e por um serviço de saúde no qual a práxis é desenvolvida com uma tecnologia de trabalho em saúde orientada para os sujeitos envolvidos na produção da saúde: docentes, estudantes, população $e$ trabalhadores. São dimensões comuns aos dois cenários desta pesquisa: a vigilância à saúde, a interdisciplinaridade, o trabalho multiprofissional, a adoção de metodologias ativas e a diversificação de cenários de ensinoaprendizagem.

A interdisciplinaridade foi tomada como dimensão central do estudo por caracterizar-se como uma das estratégias utilizadas pelos Projetos cenários da pesquisa com o propósito de transformar a prática educativa e recriar a práxis do processo de ensino-aprendizagem. Entende-se por interdisciplinaridade o movimento de construção de um conhecimento mais globalizante que rompe com as fronteiras das disciplinas e que, para tal, adota não somente a integração dos conteúdos mas um compromisso de reciprocidade diante do conhecimento como propõem Fazenda (1996) e Gadotti (2000). Assim, essa dimensão determina novas relações entre os sujeitos que interagem nesse processo: docentes, estudantes, profissionais dos serviços de saúde e população. A escolha pelos Projetos UNI como cenário da pesquisa deveu-se ao fato de adotarem a interdisciplinaridade na construção do conhecimento, seu caráter inovador e sua capacidade de apontar soluções para problemas pertencentes a uma realidade cada vez mais complexa. Aceita-se, assim, que a intervenção nessa realidade requer uma revisão de valores, atitudes, crenças, questionamentos e conceitos para servir à vastidão de conhecimentos e à rapidez com que estes são recriados e disseminados. 


\section{Percurso metodológico}

O estudo é resultado de uma pesquisa qualitativa ancorada no referencial crítico. Teve como objetivo identificar e analisar as transformações do processo de ensino de Enfermagem, captando a articulação da interdisciplinaridade nos cenários de ensino-aprendizagem de dois cursos de Enfermagem em escolas que realizam o Projeto UNI.

Os dados primários foram obtidos pela realização de um grupo focal em cada cenário, com duração de três horas e a participação de docentes e discentes. Usaram-se como referências as orientações de grupo focal de Westphal et al. (1996) e Sena \& Duarte (1999) e a questão norteadora do grupo foi: "Como você percebe o Curso de Enfermagem desta Instituição?". As falas foram gravadas e transcritas e posteriormente analisadas seguindo-se a técnica de análise de discurso como proposta por Fiorin (1993). Utilizou-se, também, um diário de campo, no qual foram registrados fatos ou aspectos do cotidiano dos pesquisadores: impressões, observações e ocorrências relacionadas aos sujeitos $e$ ao ambiente. Os dados de fonte secundária foram obtidos dos currículos dos cursos e outros documentos fornecidos pelas duas instituições que subsidiaram a compreensão do fenômeno em estudo.

A interdisciplinaridade como uma estratégia para romper paradigmas Pela análise dos dados empíricos contidos nos discursos dos sujeitos da pesquisa, inferiu-se que estes caracterizam a trajetória das escolas como imersa em um processo dinâmico, complexo e desafiador. Um dos aspectos fundamentais para perfilar e dar cor a esse movimento foi a criação, pelas instituições, de espaços de socialização do processo de ensino-aprendizagem, os quais permitiram aos atores envolvidos redefinir o conceito de educação e o papel dos docentes, estudantes e profissionais dos serviços que participam do pensar e fazer do currículo de Enfermagem. Esse movimento está ancorado nas afirmativas de Sacristán \& Gómez (1998, p.14) de que

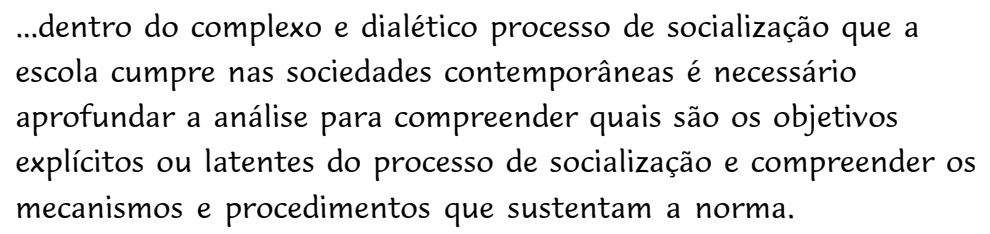

Oš entrevistados afirmam, também, que o processo de socialização desenvolvido nas escolas, em geral, busca a incorporação futura do seu egresso ao mundo do trabalho $e$ a formação do cidadão para sua intervenção na vida pública. Com essa compreensão, pode-se inferir que a construção do futuro profissional passa pela ampliação dos cenários de ensino, como estratégia para que o aluno atue criticamente nos serviços de saúde, nos espaços / domićlios dos grupos familiares, na comunidade e em outros ambientes de produção do cuidado e da atenção à saúde. Esses novos espaços exigem uma nova reflexão sobre os conceitos do processo saúde-doença e, por conseqüência, de novos fazeres que impõem um enfoque interdisciplinar e intersetorial para a solução de questões complexas e multidimensionais.

Como refere Gadotti (2000, p.223) 


\begin{abstract}
o conceito de interdisciplinaridade chega ao final deste século com a mesma conotação positiva do início do século, isto é, como forma (método) de buscar, nas ciências, um conhecimento integral e totalizante do mundo frente à fragmentação do saber e, na educação, uma forma cooperativa de trabalho para substituir procedimentos individualistas.
\end{abstract}

Para construir as mudanças necessárias nas escolas que adotam este pensamento é preciso que o projeto político pedagógico seja construído em parceria com instituições e organizações para além da Escola. A análise dos documentos sobre o programa de ensino, nos dois cursos cenários da pesquisa, revelou a força da parceria entre a universidade, o serviço de saúde e a comunidade, para viabilizar o projeto de transformar os seus modelos de ensino. A parceria foi apontada pelos informantes como a "força motriz" que potencializa cada sócio e otimiza as capacidades do conjunto em relações dinâmicas bi e trilaterais: universidade-serviço, serviço-comunidade, universidade-comunidade, universidade-serviço-comunidade, como também identificado no estudo de Sena-Chompré \& Egry (1998). Essas autoras analisaram que a parceria cria, segundo as avaliações internas dos Projetos, fortes espaços para a possibilidade de ação comunicativa, já proposta por Habermas (1987), e a invenção do fato novo entre atores sociais e instituições que intervêm no processo ensino-aprendizagem. Neste movimento, todos são responsáveis pela identificação, pela priorização e pela intervenção na solução dos problemas de saúde de indivíduos e grupos populacionais.

A análise dos dados secundários permitiu valorizar o tema parceria, ao revelar os grandes avanços obtidos pelas instituições integrantes do Projeto UNI, que pode ser caracterizado pela construção de sujeitos sociais. Os cursos objeto da investigação estão implementando estratégias para a superação da realidade existente, principalmente mediante discussão e capacitação dos docentes e dos profissionais de saúde, com o objetivo de qualificar o desempenho, que outrora seria considerado insuficiente ou inadequado para dar resposta às necessidades de formação dos profissionais para a produção dos serviços de saúde. Dessa forma, tornou-se viável a implantação do programa planejado, construindo um marco de referência que se contrapõe ao modelo anterior, conservador e tradicional, criando um novo modelo que apresenta qualidades diferentes, no pensar e no fazer do processo de formação e de produção dos serviços de saúde. A vivência dessas concepções, que se apresentam como pólos contrários, evidencia as proposições de transformação, conforme revela o enunciado a seguir:

...era do projeto, o que quer dizer; meu trabalho, minha meta, meus objetivos, minhas diretrizes e dessa forma a gente fazia a discussão $e$ conseguia institucionalizar as mudanças que a gente estava pretendendo dentro do ideário. Quer dizer de mudança do modelo assistencial, de integração com a academia, com a comunidade, $e$ essas coisas foram sendo mudadas na verdade... (relato de entrevista)

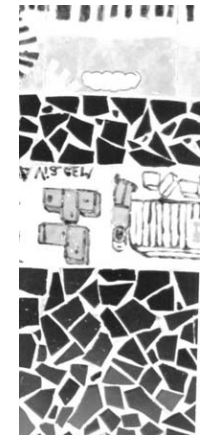


Quanto às mudanças relacionadas à prática pedagógica, foram analisados elementos que se referem à reformulação curricular nos dois projetos, permitindo detectar os avanços que vêm ocorrendo nos cenários da pesquisa $e$ os obstáculos e desafios às inovações propostas. As possibilidades de recriar, questionar e discutir o modelo de ensino adotado pelos cursos confrontam-se com uma nova realidade, construída a partir das propostas de transformação curricular. Salienta-se a ampliação dos horizontes da prática docente, despertando o desejo dos mesmos de se aprimorarem e construírem alternativas novas para o desenvolvimento do processo ensino-aprendizagem.

Outro grande desafio que os Projetos vêm enfrentando, segundo os sujeitos da pesquisa, refere-se à incorporação da pesquisa no processo ensinoaprendizagem, fundamental na construção da interdisciplinaridade.

A articulação ensino / pesquisa está sendo proposta, em um dos cursos, como um avanço do ensino na área de saúde. Parece que, acertadamente, tocase no aspecto fundamental para a almejada indissociabilidade entre ensino / pesquisa / extensão no programa de formação de profissionais de saúde, como é destacado no enunciado a seguir:

... O curso de Enfermagem teve um grande avanço, porque o nosso
aluno foi mais cedo possível para a comunidade para ter o contato
direto com os problemas reais. Então a Enfermagem teve um avanço
muito grande nessa parte da extensão, nessa parte de ir direto, de
conhecer os problemas, de atuar, de levantar, de inclusive registrar
também em termos de pesquisa, publicações, iniciação científica ...
(relato de entrevista)

A análise dos dados primários e dos documentos evidenciou as tentativas das duas instituições em tornar a ação pedagógica uma proposição de mudança contínua, sustentada na experiência vivida e na produção do conhecimento. A partir das informações dos sujeitos, captou-se que a pesquisa, ainda, é usada insuficientemente como estratégia de ensino-aprendizagem. Esta situação permite reconhecer que a velocidade das mudanças tecnológicas e sua aplicação no setor produtivo requerem das universidades um compromisso de se transformarem em espaços de experimento e formação de recursos humanos, com grande capacidade de aprender a aprender, como proposto por Delors (1999). Ampliando essa idéia, Demo (1998, p.138) analisa que o "fenômeno científico assumiu o lugar de inovação como processo, assentando-se no desafio de aprender a aprender".

A articulação do ciclo básico com o ciclo profissional, referida pelos sujeitos ao discorrerem sobre o enfoque interdisciplinar, envolve a integração dos conteúdos de suas disciplinas, além da mudança de concepção sobre o que seria fundamental para a formação do profissional de saúde e, muito especialmente, do pessoal de Enfermagem. Os enunciados a seguir revelam essa concepção:

\footnotetext{
...Mudança do que seria realmente básico para o estudante, o verdadeiro básico já denotaria a necessidade de integração de disciplinas que unissem o morfológico com o funcional, com o patológico e que não o dissociasse.
} 


\begin{abstract}
...uma oportunidade extremamente interessante do pessoal do básico se envolver na parte profissionalizante, conhecer a Unidade Básica de Saúde, conhecer a comunidade, entrar em contato com o Conselho Local de Saúde, Conselho Municipal de Saúde, creches etc. (...) Extremamente rica, uma repercussão muito grande no ciclo básico com a experiência que eles estavam desenvolvendo a ponto deles reverem até a metodologia de ensino, de avaliação. (relato de entrevista)
\end{abstract}

Ao analisar a interdisciplinaridade, Loureiro (1992) afirma que a mesma é uma necessidade para a prática de saúde, em decorrência da crescente complexidade dos problemas na área. $\mathrm{O}$ autor descreve a interdisciplinaridade como a integração de duas ou mais disciplinas diferentes, lembrando que essa integração pode ser uma simples comunicação interdisciplinar de idéias ou atingir uma interação mútua de conceitos, métodos e procedimentos. Segundo Minayo (1990), a interdisciplinaridade é indispensável para superar a atomização e a fragmentação do conhecimento em áreas circunscritas. A autora analisa a interdisciplinaridade para serventia do saber, em função da compreensão e da busca de soluções às questões cada vez mais complexas da sociedade contemporânea.

No presente estudo, os sujeitos destacam como finalidades fundamentais da interdisciplinaridade: responder a questões complexas, abordar questões amplas, explorar relações entre disciplinas e profissões, solucionar problemas que ultrapassem os limites de uma disciplina e alcançar a unidade do conhecimento no processo de ensino-aprendizagem.

Os dados indicam, ainda, que a adoção do enfoque interdisciplinar nos currículos tem como proposta uma orientação para o estabelecimento da esquecida síntese dos conhecimentos, não apenas pela integração de conteúdos produzidos nos vários campos de estudo, de modo a ver a realidade globalmente, mas, sobretudo, pela associação dialética entre as dimensões polares como, por exemplo, teoria e prática, ação e reflexão, generalização e especialização, curativo e preventivo, ensino e avaliação, meios e fins, conteúdos e processos, indivíduo e sociedade, dentre outras, confirmando as idéias de Minayo (1990).

Os sujeitos indicam que o objetivo da interdisciplinaridade é, portanto, promover a compreensão da complexidade da realidade e a superação da visão restrita de mundo buscando, ao mesmo tempo, resgatar a centralidade do homem, na realidade e na produção do conhecimento, de modo a permitir uma melhor apreensão da realidade e do homem como um ser determinado e determinante.

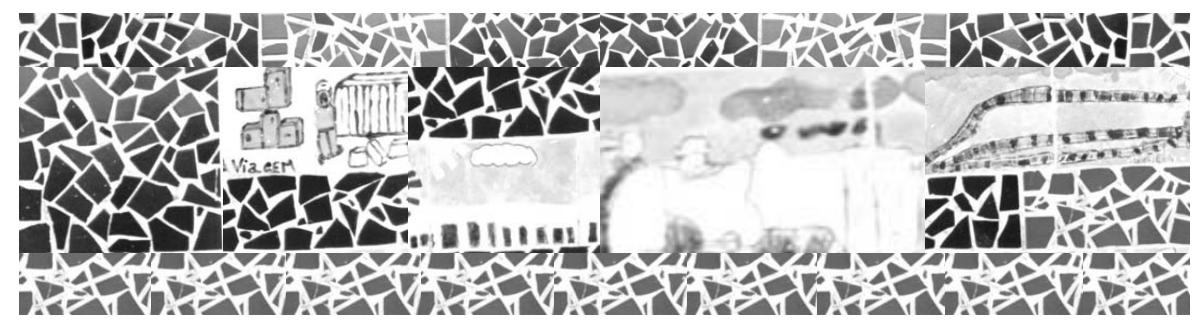


Assim, a interdisciplinaridade é defendida pelos sujeitos como uma resposta à necessidade de superar a visão fragmentada na produção do conhecimento, como também de articular e produzir coerência entre os múltiplos fragmentos que estão postos no acervo de conhecimentos da humanidade (Loureiro, 1992). Trata-se, assim, de um esforço que vem sendo realizado nos cenários deste estudo pelos docentes e discentes para promover a elaboração de sínteses que desenvolvam a contínua construção do conhecimento, utilizando-se de representações da realidade (Sakai, 1994).

Mesmo reconhecendo os avanços, os sujeitos indicam ser a interdisciplinaridade um dos grandes desafios na construção do conhecimento, no currículo integrado adotado pelos cursos. Apontam, ainda, que a aproximação dos docentes do ciclo básico com a realidade com a qual os alunos vão encontrar quando se tornarem profissionais constitui um facilitador para a associação dos conteúdos, que passam a ser vistos não mais de forma dissociada e repetitiva, como descrito no enunciado a seguir:

...um dos pontos importantes do PAPIENS foi o fato de que, ao mesmo tempo que a gente trabalhava com os alunos, a gente trabalhava também tanto com os profissionais como com os professores que eram em grande parte da área básica. Então, esses professores que nunca viram e nem tiveram vivência da área de saúde, passaram a ter. (...) Isso faz com que o professor veja que tipo de problema os alunos vão enfrentar no futuro como profissionais. (...) Isso possibilita uma maior integração do pessoal do básico com o pessoal da área profissional.(...) Além dos projetos de ensino, tiveram outros também como os projetos de apoio de pesquisas interdepartamentais, devendo ter pelo menos um da área profissionalizante. (relato de entrevista)

Os dados primários indicam que o exercício da interdisciplinaridade, nos cursos cenários deste estudo, fora do contexto da sala de aula, implica a vivência da parceria universidade / serviço / comunidade e permite a articulação dos conteúdos numa realidade concreta. Dessa forma, o currículo com desenho interdisciplinar é apontado pelos entrevistados como mais efetivo, por valorizar experiências conjuntas e criativas dos docentes, discentes e profissionais dos serviços de saúde.

Segundo Sakai (1994), o valor da interdisciplinaridade também tem sido identificado e reconhecido, no cuidado do usuário, por várias profissões de saúde. Entretanto, raramente é praticada nos setores clínico ou educacional. Dessa forma, as tendências e abordagens do modelo interdisciplinar, propostas pelos Projetos UNI nos cenários deste estudo, podem ser apontadas como inovadoras, uma vez que rompem com o modelo tradicional e, mesmo estando, ainda, em implementação, permitem a articulação de conteúdos e práticas pedagógicas em áreas críticas, possibilitando a integração das disciplinas do ciclo básico com as do ciclo profissional. $O$ enunciado que se segue retrata essa percepção:

...agora não existe mais a disciplina do ciclo básico, a disciplina do 
ciclo profissional, existem conhecimentos que no conjunto fornecem subsídios para a formação e capacitação do aluno. Foram criados módulos de orientação para o estudante. Afinal, o que é básico para um estudante? Eu não tenho a pretensão de saber responder.... (relato de entrevista)

Os sujeitos apontam que a avaliação do processo ensino-aprendizagem não poderia deixar de ser inovadora, adotando a avaliação formativa, de finalidade social, que busca diferenciar-se das modalidades tradicionais de pontuação para adotar como parâmetro o conceito de competência sendo, portanto, coerente com a interdisciplinaridade que propõe o fim da fragmentação do conhecimento. $\mathrm{O}$ enunciado a seguir expressa as percepções de um dos sujeitos acerca do modelo de avaliação adotado por um dos cursos cenários investigados:

Eu acho que entra aí o conceito do que é buscar uma avaliação formativa que permita uma prescrição individual, que tem inclusive uma finalidade social. Afinal de contas até quando nós iríamos somar uma laranja boa com uma um pouco estragada? (....) é fundamental que se priorize o individual e o que realmente interessa que os alunos saibam... (relato de entrevista)

Contribuindo para a análise do sistema de avaliação, Hoffmann (1995) sugere que a nova perspectiva de avaliação exige do educador uma concepção do indivíduo como sujeito inserido no contexto de sua realidade social e política, que constrói e recria seu auto-conhecimento. Essa perspectiva exige, também, do aluno a formulação de seus próprios conceitos, já que as avaliações não medem resultados e aspectos pontuais e nem mesmo negligenciam os aspectos fundamentais do processo de aprender a aprender, a fazer, a ser e a trabalhar, como proposto por Delors (1999). Os sujeitos assinalam que os cursos adotaram processos avaliativos mais justos e menos estereotipadores de "respostas corretas". Esse pensamento pode ser verificado no enunciado que se segue:

Os modelos de avaliação melhoram e inclusive acredito que não estejam ainda no ponto que deveriam estar, mas pelo menos os professores estão muito mais preocupados com o sistema de avaliação. A auto-avaliação foi nosso grande gancho de trabalho, porque os alunos não tinham essa habilidade, e eu acho que ninguém se avalia melhor do que a gente mesmo. Então, o aluno quando desde o começo se auto-avalia já está fazendo um exercício profissional, porque não é teu chefe que te avalia; é você mesmo que se auto-avalia e é você mesmo que pode melhorar e corrigir suas faltas... (relato de entrevista)

Bordenave E Pereira (2001, p.70) afirmam que a avaliação é um aspecto fundamental no processo de inovação do ensino. Para os autores, apesar de ser um tema/situação/problema de domínio dos docentes, a questão é que se "não 
se muda a avaliação, será muito difícil fazer alguma coisa que tenha consistência, seja eficiente e que resista ao Teste do Tempo". Afirmam, também, que a avaliação formativa é a base do processo ensino-aprendizagem baseado em problema e centrado no estudante. Pode-se inferir que esses pressupostos se alcançam com a adoção da interdisciplinaridade, pois esta permite "a identificação precoce dos problemas que o aluno pode ter em seu trabalho e, ao fazê-lo, permite ao estudante identificar as suas dificuldades e buscar os caminhos de correção" (Bordenave E Pereira, 2001, p.70).

As informações dos docentes investigados indicam que, no processo de inovação, os mesmos enfrentam uma grande dificuldade em superar os modelos de avaliação orientados para averiguação de aquisição de conhecimento, que enfatizam as habilidades cognitivas, e em adotar um processo de avaliação, com enfoque interdisciplinar, que articula diferentes áreas do conhecimento de fazeres e de atitudes no processo ensinoaprendizagem e assistencial. Os sujeitos revelaram, ainda, que na avaliação formativa há possibilidade de conhecer as limitações e potencialidades do aluno na sua aprendizagem, em seus aspectos cognitivos, de aquisição de habilidades e de atitudes / comportamentos.

Em uma das instituições da pesquisa, o processo de avaliação ainda está orientado pelo currículo organizado por disciplinas. No outro curso tem uma aproximação do modelo de avaliação inovador orientado para a competência dos estudantes e para o enfoque interdisciplinar, facilitado pelo currículo integrado, como podemos perceber no enunciado que se segue:

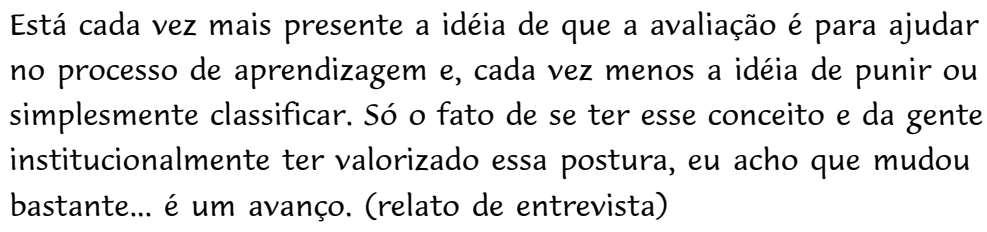

Os sujeitos afirmam que os profissionais de saúde, freqüentemente, são educados com uma visão fragmentada e experimentam uma prática com pouca cooperação entre as disciplinas e os setores da sociedade que têm como responsabilidade resolver os problemas de saúde da população. Assinalam, também, que a fragmentação é um problema por causa da sobreposição de papéis, criando poderes paralelos do pessoal de saúde, com nichos em suas respectivas áreas do sistema de saúde e de ensino, que prejudicam a relação com os demais setores. A análise dos dados permite inferir, ainda, que a conceitualização do processo saúde-doença adotada nas escolas é um desafio, pois cada vez mais há necessidade de se adotar concepções mais abrangentes de vigilância à saúde em contraposição à natureza setorial que caracteriza a atuação dos profissionais da área. Assim, a interdisciplinaridade é uma possibilidade de romper com essas amarras e construir novas relações de cooperação, colaboração e associação entre os profissionais e comunidade para solucionar os problemas de saúde no bojo dos problemas sociais.

\section{Considerações finais}

Os dados empíricos permitem concluir que, nos cursos investigados, a 
interdisciplinaridade pressupõe a possibilidade de reduzir a hegemonia dos saberes, de projetá-los numa mesma dimensão epistemológica, sem negar os limites e a especificidade das disciplinas. Permitem indicar, ainda, que há necessidade de as instituições de ensino definirem um projeto políticopedagógico, no qual esteja priorizada a parceria universidade / serviços / comunidade, para propiciar a formação de profissionais com perfil necessário para atender à demanda e às necessidades de saúde da população, abrangendo a saúde nas dimensões biológica, do estilo de vida, das relações dos seres humanos com o meio ambiente e os serviços de saúde.

$O$ estudo revela também que a interdisciplinaridade tem exercido um relevante papel em face da construção de um novo modelo de ensino nos cursos cenários da pesquisa. Os suportes técnico, metodológico e financeiro, promovidos pelos Projetos UNI, têm permitido avanços dentro das instituições de ensino, nos serviços e na comunidade, construindo $e$ reconstruindo o cotidiano do processo de educar, de aprender e ser em uma relação de acumulação qualitativa.

Os aspectos relativos à interdisciplinaridade, analisados no estudo, demonstram que a mesma tem um caráter positivo no processo de aprendizagem, produzindo situações de superação, tanto na construção de um novo paradigma do ensino quanto no relacionamento deste com o processo saúde-doença. Fica evidenciado seu caráter processual e gradual, exigindo tempo para ser absorvido pela instituição e liberdade para identificar as questões a serem inovadas em um contínuo processo de pensar, agir, e transformar.

Referências

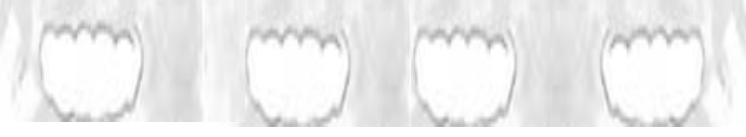

ALMEIDA, M.; FEUERWERKER, L.; LHANOS, C. M. (Orgs.). A educação dos profissionais de saúde na América Latina: teoria e prática de um movimento de mudança. São Paulo: Hucitec, 1999.

BORDENAVE, J. D.; PEREIRA, A. M. Estratégias de ensino-aprendizagem. 22.ed. Petrópolis: Vozes, 2001.

DELORS, J. (Org.). Educação: um tesouro a descobrir. Relatório para a UNESCO da Comissão Internacional sobre Educação para o século XXI. 3.ed. São Paulo: Cortez, 1999.

DEMO, P. Desafios modernos da Educação. Petrópolis: Vozes, 1998.

FAZENDA, I. C. A. (Org). Práticas interdisciplinares na escola. 3.ed. São Paulo: Cortez, 1996.

FIORIN, J. L. Elementos de análise de discurso. São Paulo: Contexto/EDUSP, 1993.

GADOTTI, M. A Educação contra a Educação. 2.ed. Rio de Janeiro: Paz e Terra, 1982.

GADOTTI, M. Perspectivas atuais da Educação. Porto Alegre: Artes Médicas Sul, 2000.

HABERMAS, J. Conhecimento e Interesse. Rio de Janeiro: Guanabara, 1987.

HOFFMANN, J. Avaliação: mito e desafio, uma perspectiva construtiva. Porto Alegre: Mediação, 1995.

LOUREIRO, S. Interdisciplinaridade e multidisciplinariedade na prática da Saúde Coletiva: uma utopia possível? In: OFICINA DE TRABALHO: ESTRATÉGIAS PARA EL TRABAJO INTERDISCIPLINAR E MULTIPROFISIONAL EN LA PRÁCTICA DE LA SALUD COLECTIVA, 1992, Caracas. Relatório... Caracas, 1992. p.1-20. 
SENA, R. S.; LEITE, J. C. A.; SILVA, K. L.; COSTA, F. M.

MINAYO, M. C. S. Interdisciplinaridade: uma questão que atravessa o saber, o poder e o mundo vivido. In: SEMINÁRIO DE ESTUDOS DO PROGRAMA DE APOIO À REFORMA SANITÁRIA, 1., 1990, Rio de Janeiro.

Anais... Rio de Janeiro, 1990. p.1-12.

SACRISTÁN, J. G.; GÓMEZ, A. I. P. Compreender e transformar o ensino. Porto Alegre: ARTMED, 1998.

SAKAI, M. H. Educação inter/multiprofissional: o suo do PBL em um currículo multiprofissional. Olho Mágico, v.1, n.1, p.21, set 1994.

SENA-CHOMPRÉ, R. R.; EGRY, E. Y. A Enfermagem nos Projetos UNI: contribuição para um novo projeto político para a Enfermagem brasileira. São Paulo: HUCITEC, 1998.

VÁSQUEZ, A. S. Filosofia da Praxis. 4.ed. Rio de Janeiro: Paz e Terra, 1997.

SENA, R. R.; DUARTE, E. D. Contribuição para a construção do percurso metodológico do Projeto Classificação das Práticas de Enfermagem em Saúde Coletiva. In: CHIANCA, T. C. M.; ANTUNES, M. J.

(Orgs.). Classificação Internacional das Práticas de Enfermagem em Saúde Coletiva: CIPESC. Brasília: Associação Brasileira de Enfermagem, 1999. p.325-33.

WESTPHAL, M. F.; BÓGUS, C. M.; FARIA, M. M. Grupos focais: experiências precursoras em programas educativos em saúde no Brasil. Bol. Oficina Sanit. Panam, v.120, n.6, p.472-81, 1996.

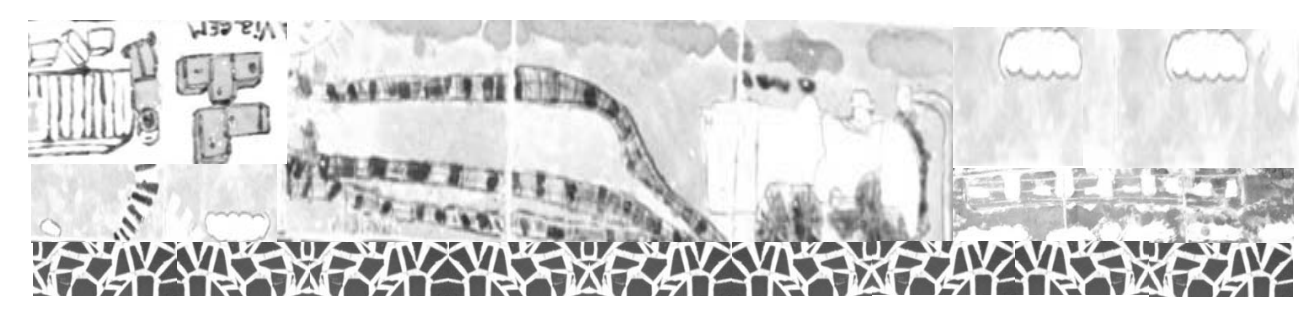

SENA, R. S., LEITE, J. C. A., SILVA, K. L., COSTA, F. M. Proyecto Uni: escenario de aprender, pensar y construir la interdisciplinariedad en la práctica pedagógica de la enfermería, Interface - Comunic, Saúde, Educ, v.7, n.13, p.79-90, 2003.

El estudio analiza la incorporación de un enfoque interdisciplinar en dos cursos de Enfermería en Brasil que desarrollan el Proyecto UNI. Se caracteriza como un estudio descriptivo cualitativo, utilizando el materialismo histórico dialéctico como referencia teórico-metodológica. El estudio tiene el objetivo de analizar las transformaciones ocurridas en el proceso de enseñaza de los cursos de enfermería, teniendo como énfasis la interdisciplinariedad. Los datos primarios fueron tomados utilizando entrevistas en grupo focal, docentes y alumnos de los cursos y enfermeros de los servicios. Los datos de fuentes secundarias fueron obtenidos del análisis documental de currículos y otros documentos de las universidades escenarios del estudio. Se identificó que los cursos están utilizando la interdisciplinariedad como estrategia para la superación de la organización del currículo por disciplina. Los docentes relatan las dificultades del trabajo con ese enfoque, apuntando la formación biologicista como uno de los determinantes de esta dificultad. Se concluye que el énfasis en la interdisciplinariedad y en el trabajo en equipo ha exigido la adopción de metodologías activas de enseñaza y ha contribuido en la transformación del modelo de enseñanza de enfermería.

PALABRAS CLAVE: enseñanza; enfermería; interdisciplinariedad; practica profesional. 